\title{
EMPLOYMENT OF ATR-FTIR AND HPLC-UV METHOD FOR DETECTION AND QUANTIFICATION OF ANDROGRAPHOLIDE
}

\section{OKTAVIA INDRATI ${ }^{1,2}$, RONNY MARTIEN ${ }^{1}$, ABDUL ROHMAN ${ }^{3}$, AKHMAD KHARIS NUGROHO ${ }^{*}$}

\begin{abstract}
${ }^{1}$ Department of Pharmaceutics, Faculty of Pharmacy, Universitas Gadjah Mada, Sekip Utara, Yogyakarta Indonesia 55281, ${ }^{2}$ Department of Pharmacy, Faculty of Mathematics and Natural Sciences, Universitas Islam Indonesia, Jl. Kaliurang Km 14,5 Sleman Yogyakarta Indonesia 55584, ${ }^{3}$ Department of Pharmaceutical Chemistry, Faculty of Pharmacy, Universitas Gadjah Mada, Sekip Utara, Yogyakarta Indonesia 55281 Email: oktavia.indrati@uii.ac.id
\end{abstract}

Received: 23 Jul 2018, Revised and Accepted: 04 Sep 2018

\section{ABSTRACT}

Objective: The purpose of this present study was to describe the employment of infrared (IR) spectroscopy and high-performance liquid chromatography with ultraviolet detection (HPLC-UV) method in determining the identity and purity of bulk material containing andrographolide.

Methods: Attenuated total reflectance (ATR)-Fourier transform infrared (FTIR) spectroscopy was carried out in transmittance mode to investigate the molecular vibration of the bulk material component and the similarity of functional groups between bulk material and standard andrographolide. Meanwhile, the liquid chromatographic analyses were performed on a reversed-phase C18 column and under UV detection at 224 $\mathrm{nm}$ to determine the andrographolide content of the bulk material.

Results: The obtained ATR-FTIR spectra indicated that functional group of the bulk material were in close similarity with those of standard andrographolide. The linearity of the evaluated method achieved over a concentration range of 1 to $60 \mu \mathrm{g} / \mathrm{ml}$ with a high correlation coefficient (0.999). By using the studied HPLC-UV method, the andrographolide of bulk material was found to be $98.12 \%$ (retention time of $2.58 \mathrm{~min}$ ).

Conclusion: The studied HPLC-UV method of andrographolide determination is accurate, precise, selective, and brief in terms of analysis time. The studied method, therefore, provides a rapid and reliable assessment for identifying and determining the purity of andrographolide bulk material.

Keywords: Andrographolide, Bulk material, Determination, HPLC-UV, Identity, Purity

(C) 2018 The Authors. Published by Innovare Academic Sciences Pvt Ltd. This is an open-access article under the CC BY license (http://creativecommons.org/licenses/by/4.0/) DOI: http://dx.doi.org/10.22159/ijap.2018v10i6.28691

\section{INTRODUCTION}

Andrographolide (fig. 1) is a diterpenoid substance isolated from the medicinal plant of Andrographis paniculata. This compound becomes the point of interest since A paniculata herb is widely used as a traditional medicine in several Asian countries such as India, Indonesia, China, Malaysia, and Thailand [1,2]. A large number of studies were conducted to isolate, identify, and quantify this substance [3-5] as well as assess its pharmacological activities [6-8], and its safety $[9,10]$. Andrographolide is reported to exhibit various biological activities, including antidiabetic [11], anticancer, anti-inflammatory [6], antivirus, and hepatoprotective activities. Despite the many pharmacological activities, it is reported that andrographolide has poor aqueous solubility and is extensively metabolized leading to its low oral bioavailability $[2,12]$. Hence, numerous studies were performed to develop andrographolide containing dosage form in order to enhance the acceptability, solubility, and bioavailability of this bioactive compound. Numerous dosage forms such as microcrystal [13], microemulsion [14], micelle [15], nanoparticle[16], solid lipid nanoparticle [17], spray-dried [18] and suspension [19] of andrographolide have been successfully developed.

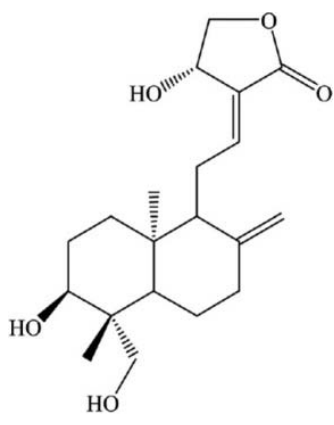

Fig. 1: The chemical structure of andrographolide
The quality of the bulk material is an important factor that has to be considered during a dosage form development process and routine analysis before drug manufacturing. Bulk material quality affects the quality of the finished product. Several authors have studied the quantification of andrographolide isolated from Andrographis paniculata herbs $[3,4,20,21]$, but none of them reported the determination of andrographolide bulk material's identity and purity. ATR-FTIR spectroscopy offers a rapid and direct analytical technique without sample preparation as the advantage [22, 23]. Meanwhile, HPLC-UV method is a simple and rapid technique for quantification of drug substance compared to other techniques [24], which becomes the method of choice for bulk and dosage form analysis [25-28]. Therefore, this study aims to describe the determination of andrographolide content in bulk material employing infrared spectroscopy and HPLC-UV method.

\section{MATERIALS AND METHODS}

\section{Chemical and reagents}

Andrographolide bulk material was purchased from Sinobright Pharmaceutical, China while andrographolide standard (98\%) was obtained from Sigma. Methanol for HPLC (J. T Baker) was used as the mobile phase. ATR-FTIR(Attenuated total reflectance-Fourier transform
infrared)

The powder of bulk material and standard andrographolide were investigated in ATR-FTIR to determine the molecular functional groups of the component and the similarity between these two samples. IR spectra were recorded by using Spectrum Two FTIR spectrometer (Perkin Elmer, USA) with a single reflectance horizontal ATR cell. The analyses were made in transmittance mode with a small amount of sample deposited on the ATR crystal. The transmittance was measured in the frequency range from $400 \mathrm{~cm}^{-1}$ to $4000 \mathrm{~cm}^{-1}$ with resolution of $4 \mathrm{~cm}^{-1}$. 


\section{Chromatographic condition}

This study was conducted using Waters liquid chromatography system (e2695) that was equipped with UV detector (2486). A Sunfire C-18 column $(150 \times 4.6 \mathrm{~mm}, 5 \mu \mathrm{m})$ was used as the static phase in the chromatographic separation process. The mobile phase consisted of methanol: water (67:33) that was filtered through a $0.45 \mu \mathrm{m}$ nylon membrane and sonicated prior to using. The flow rate of the mobile phase was set at $1 \mathrm{ml} / \mathrm{min}$. Meanwhile, the detection wavelength was set at $224 \mathrm{~nm}$. The injection volume was kept at $20 \mu \mathrm{l}$. Data acquisition and analyses were performed using Empower software. This chromatographic condition was adapted from a previously reported technique [3] with a slight modification in the ratio of mobile phase and also detection wavelength.

\section{Stock solution preparation}

A stock solution of andrographolide $(250 \mu \mathrm{g} / \mathrm{ml})$ was prepared by dissolving $12.5 \mathrm{mg}$ of andrographolide standard in $50 \mathrm{ml}$ methanol. This solution was then diluted with methanol to produce a series of working standard dilution.

\section{System suitability}

Six replicate injections of bulk material containing andrographolide (30 $\mu \mathrm{g} / \mathrm{ml}$ ) were evaluated for system suitability. The evaluated parameters were retention time, tailing factor, selectivity, and resolution.

\section{Linearity}

Linearity was evaluated by injecting a series of concentrations of andrographolide standard ranging from 1 to $60 \mu \mathrm{g} / \mathrm{ml}$. Each level of andrographolide concentration was prepared in triplicate manner. A linear regression analysis was performed between the employed concentration and peak areas obtained.

\section{Precision}

Precision was evaluated in terms of repeatability and inter-day precision. Repeatability of the HPLC-UV method was determined by repeatedly (n = 6) injecting a solution of bulk material $(30 \mu \mathrm{g} / \mathrm{ml})$ and then recording the chromatogram. Meanwhile, the inter-day precisions were analysed by measuring the corresponding responses 3 times on 3 different days for 1 concentration of andrographolide $(30 \mu \mathrm{g} / \mathrm{ml})$. The results were expressed as a percentage of relative standard deviation (RSD).

\section{Accuracy}

The accuracy of the method was tested by fortifying samples (bulk material solution) with three different concentration of standard andrographolide and determining the recovery of the added standard. Three replicates of each concentration level were prepared, filtered and injected. The percentage recoveries of andrographolide were then determined.

\section{Limit of detection (LOD) and limit of quantification (LOQ)}

Limit of detection (LOD) was defined as the lowest concentration of andrographolide resulting in a signal-to-noise ratio of 3:1. Meanwhile, the limit of quantification (LOD) was expressed as a signal-to-noise ratio of 10:1. LOD and LOQ of the studied method were determined by using the calibration curve data, $3.3 \mathrm{SD} / \mathrm{S}$ and $10 \mathrm{SD} / \mathrm{S}$ respectively, where SD is the standard deviation of $y$ intercepts and $\mathrm{S}$ is the slope obtained from the calibration curve. Varied concentrations ranging from 1 to $60 \mu \mathrm{g} / \mathrm{ml}$ were prepared and analysed to obtain these values.

\section{Bulk material sample preparation}

About $12.5 \mathrm{mg}$ of bulk material powder was accurately weighed and dissolved in $50 \mathrm{ml}$ of methanol. The aliquot was then taken, diluted, and filtered using a $0.45 \mathrm{~mm}$ membrane. It was then injected under the chromatographic condition as described earlier to determine the andrographolide content.

\section{RESULTS AND DISCUSSION}

\section{ATR-FTIR}

ATR-FTIR spectroscopy was carried out to study the similarity of the functional group between standard andrographolide and bulk material. The FTIR spectra of the bulk material showed a characteristic of lactone absorption band at $1722 \mathrm{~cm}^{-1}, \mathrm{C}=\mathrm{C}$ band at $1674 \mathrm{~cm}^{-1}, \mathrm{C}-0-\mathrm{C}$ band at $1218 \mathrm{~cm}^{-1}$, and methylene at $906 \mathrm{~cm}^{-}$ ${ }^{1}$ (fig. 2). These absorption bands were also detected in previous studies of andrographolide IR spectra reported by other authors $[20,29,30]$. The obtained ATR-FTIR spectra revealed that there was a close similarity between the transmittance signals of standard andrographolide and those of bulk material. This result confirmed the identification of the bulk material as andrographolide.

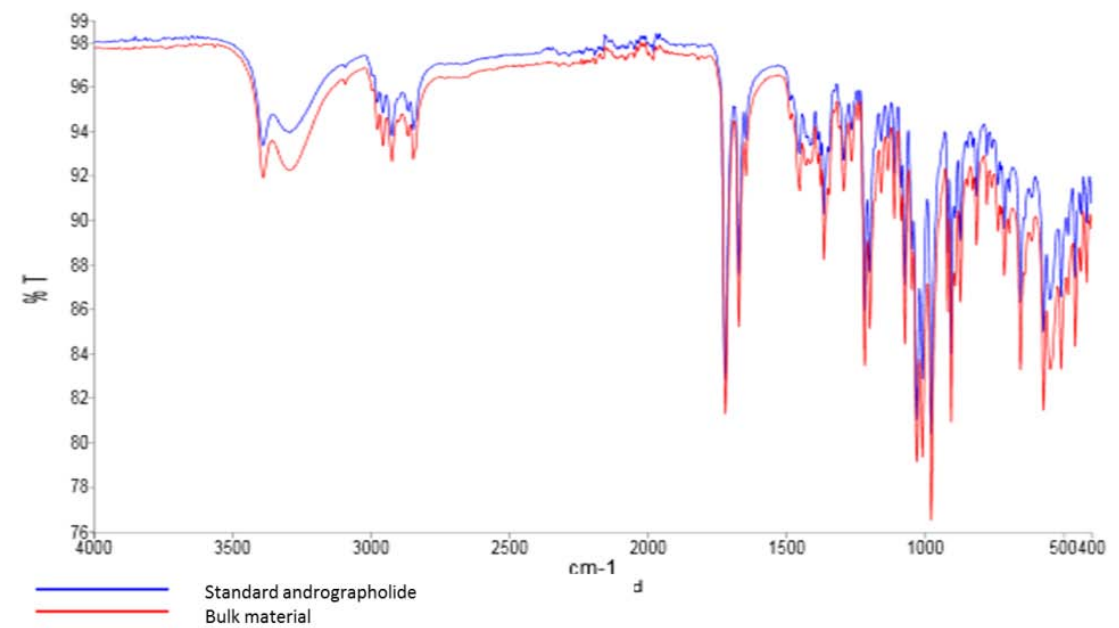

Fig. 2: ATR-FTIR spectra of standard andrographolide and bulk material

\section{Wavelength selection}

Andrographolide standard in methanol was scanned from 190 to $400 \mathrm{~nm}$ using UV-Vis spectrophotometer to assess the maximum wavelength of andrographolide absorbance. The maximum andrographolide absorbance was observed at a wavelength of 224 $\mathrm{nm}$. Similar wavelength was also reported by other researchers [2]. Thus, this wavelength was selected for future analysis.

\section{System suitability}

These chromatographic conditions delivered a chromatogram having a good repeatability of peak response (standard deviation of retention time is 0.001 ) and low tailing factor $(0.94)$. The resolution between andrographolide and its nearest peak was found to be 2.95 , which was higher than the required level (resolution/Rs $>2$ ). These parameters indicate that the system is suitable for the analysis. The 
results for system suitability were found to be within the acceptable limits.

\section{Linearity}

The method presented linearity over the evaluated concentration range of 1 to $60 \mu \mathrm{g} / \mathrm{ml}$ which is shown by a high correlation coefficient (0.999). This result indicated that the linearity of the studied method complies with the regulatory requirement. The regression equation for the calibration curve was $\mathrm{y}=38486 \mathrm{x}-$ 7716.4, where $\mathrm{y}$ is the peak area and $\mathrm{x}$ is the concentration of andrographolide $(\mu \mathrm{g} / \mathrm{ml})$. The calibration curve of series concentrations of andrographolide in methanol is shown in fig. 3.

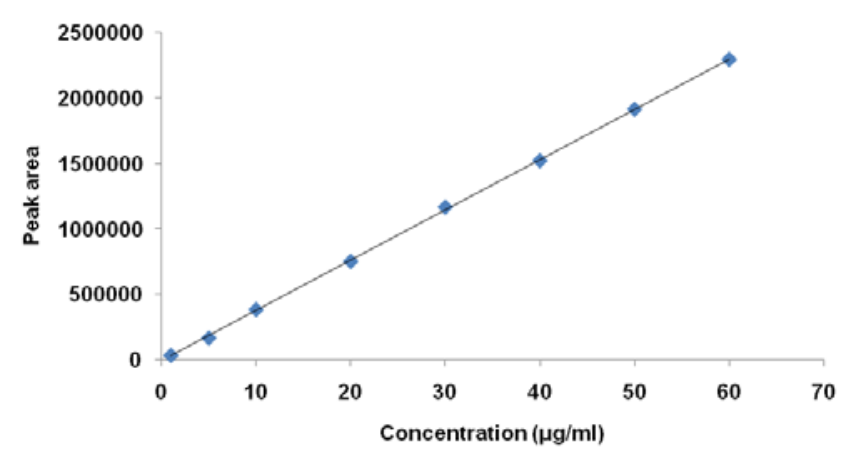

Fig. 3: Calibration curve of andrographolide in methanol

\section{Precision, accuracy, LOD, and LOQ}

The relative standard deviations for repeatability and inter-day precisions were found to be less than $2 \%$ (table 1), indicating that the studied method was precise. The overlay chromatogram obtained from precision determination is presented in fig. 4. In addition, accuracy was found to be high, having a mean percentage recovery of $99-101 \%$ (table 2). LOD and LOQ were found to be 1.0 and $3.34 \mu \mathrm{g} / \mathrm{ml}$ respectively. This result indicated that the method has proper repeatability, low inter-day variability, and accuracy in determining the andrographolide content of the bulk material. The average retention time of andrographolide was 2.58 min under the studied condition. This retention time was faster than that reported by a previous study (4.3 min) [3]. Having faster retention time can be beneficial in terms of analysis time and amount of mobile phase required for routine analysis.

Table 1: Results of a precision study of andrographolide

\begin{tabular}{llll}
\hline Parameter & Mean of peak area & SD & RSD (\%) \\
\hline Repeatability* & 1117621.67 & 10582.46 & 0.95 \\
Inter-day precision** $^{*}$ & 1129007 & 11608.35 & 1.03 \\
\hline
\end{tabular}

${ }^{*}$ result expressed in mean $(n=6),{ }^{* *}$ result expressed in mean $(n=3), S D=$ standard deviation, $\mathrm{RSD}=$ relative standard deviation

Table 2: Results of recovery study of andrographolide

\begin{tabular}{|c|c|c|c|c|c|c|}
\hline \multirow{2}{*}{$\begin{array}{l}\text { Amount of bulk } \\
\text { material }(\mu \mathrm{g} / \mathrm{ml})\end{array}$} & \multirow{2}{*}{$\begin{array}{l}\text { Amount of andrographolide standard } \\
\text { added }(\mu \mathrm{g} / \mathrm{ml})\end{array}$} & \multicolumn{3}{|c|}{ Amount of andrographolide found $(\mu \mathrm{g} / \mathrm{ml})$} & \multirow{2}{*}{$\begin{array}{l}\text { Recovery } \pm S D^{*} \\
(\%)\end{array}$} & \multirow{2}{*}{$\begin{array}{l}\text { RSD** } \\
(\%)\end{array}$} \\
\hline & & 1 & 2 & 3 & & \\
\hline 20.89 & 10 & 30.89 & 30.99 & 31.22 & $99.29 \pm 1.62$ & 1.63 \\
\hline 20.89 & 20 & 41.29 & 40.69 & 40.96 & $101.53 \pm 1.53$ & 1.51 \\
\hline 20.89 & 30 & 52.38 & 51.48 & 52.28 & $101.91 \pm 1.6$ & 1.58 \\
\hline
\end{tabular}

*result expressed in mean $(\mathrm{n}=3), \mathrm{SD}=$ standard deviation, $\mathrm{RSD}=$ relative standard deviation

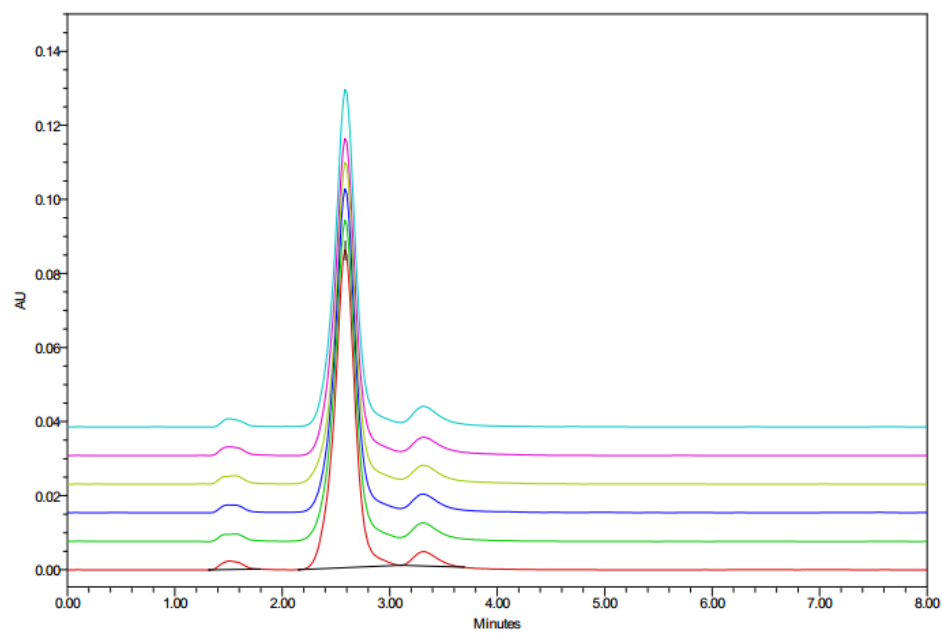

Fig. 4: The overlay chromatogram of andrographolide in bulk material $(n=6)$ 


\section{Andrographolide content determination}

Despite the slight modification in the wavelength detection and proportion of mobile phase compared to previous research, the evaluated method showed a proper precision result, good accuracy, and shorter retention time. The studied method was then employed to determine the andrographolide content of the bulk material. The percentage of andrographolide in the bulk material was found to be $98.12 \%$.

\section{CONCLUSION}

This study demonstrated that verified HPLC-UV method of andrographolide determination is accurate, precise, selective, and short in terms of analysis time. Besides, both of ATR-FTIR spectroscopy and HPLC-UV were successfully employed in the determination of identity and purity of andrographolide in bulk material. By employing studied HPLC-UV method, the andrographolide content of bulk material was found to be $98.12 \%$.

\section{ACKNOWLEDGMENT}

The authors are grateful to Indonesia Endowment Fund for Education (BUDI-LPDP) for providing financial support to conduct these studies.

\section{CONFLICT OF INTERESTS}

Declared none

\section{REFERENCES}

1. Aromdee C. Andrographolide: progression in its modifications and applications-a patent review (2012-2014). Expert Opin Ther Pat 2014;24:1129-38.

2. Pawar A, Rajalakshmi S, Mehta P, Shaikh K, Bothiraja C. Strategies for formulation development of andrographolide. RSC Adv 2016;6:69282-300.

3. Syukri Y, Martien R, Lukitaningsih E, Nugroho AE. Quantification of andrographolide isolated from Andrographis paniculata nees obtained from a traditional market in Yogyakarta using validated HPLC. Indones J Chem 2016;16:190-7.

4. Kumar S, Dhanani T, Shah S. Extraction of three bioactive diterpenoids from Andrographis paniculata: effect of the extraction techniques on extract composition and quantification of three andrographolides using high-performance liquid chromatography. J Chromatogr Sci 2014;52:1043-50.

5. Chao WW, Lin BF. Isolation and identification of bioactive compounds in Andrographis paniculata (Chuanxinlian). Chin Med 2010;5:17.

6. Lim JCW, Chan TK, Ng DS, Sagineedu SR, Stanslas J, Wong WF. Andrographolide and its analogues: versatile bioactive molecules for combating inflammation and cancer: andrographolide for inflammation and cancer. Clin Exp Pharmacol Physiol 2012;39:300-10.

7. Chen HW, Huang CS, Li CC, Lin AH, Huang YJ, Wang TS, et al. Bioavailability of andrographolide and protection against carbon tetrachloride-induced oxidative damage in rats. Toxicol Appl Pharmacol 2014;280:1-9.

8. Warditiani NK, Susanti NMP, Arisanti CIS, Putri NPRD, Wirasuta IMAG. Antidyslipidemia and antioxidant activity of andrographolide compound from sambiloto (Andrographis paniculata) herb. Int J Pharm Pharm Sci 2017;9:59-65.

9. Bothiraja C, Pawar AP, Shende VS, Joshi PP. Acute and subacute toxicity study of andrographolide bioactive in rodents: evidence for the medicinal use as alternative medicine. Comp Clin Pathol 2013;22:1123-8.

10. Sharifuddin Y, Parry EM, Parry JM. The genotoxicity and cytotoxicity assessments of andrographolide in vitro. Food Chem Toxicol 2012;50:1393-8.

11. Subramanian R, Zaini Asmawi M, Sadikun A. A bitter plant with a sweet future? A comprehensive review of an oriental medicinal plant: Andrographis paniculata. Phytochem Rev 2012;11:39-75

12. Ye L, Wang T, Tang L, Liu W, Yang Z, Zhou J, et al. Poor oral bioavailability of a promising anticancer agent andro- grapholide is due to extensive metabolism and efflux by P-glycoprotein. J Pharm Sci 2011;100:5007-17.

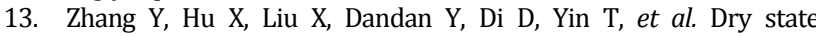
microcrystals stabilized by an HPMC film to improve the bioavailability of andrographolide. Int J Pharm 2015;493:214-23.

14. Sermkaew N, Ketjinda W, Boonme P, Phadoongsombut N, Wiwattanapatapee R. Liquid and solid self-micro emulsifying drug delivery systems for improving the oral bioavailability of andrographolide from a crude extract of Andrographis paniculata. Eur J Pharm Sci 2013;50:459-66.

15. Zhang J, Li Y, Gao W, Repka MA, Wang Y, Chen M. Andrographolide-loaded PLGA-PEG-PLGA micelles to improve its bioavailability and anticancer efficacy. Expert Opin Drug Delivery 2014;11:1367-80.

16. Ghosh P, Mondal S, Bera T. Preparation and characterization of andrographolide nanoparticles for visceral leishmaniasis chemotherapy: in vitro and in vivo evaluations. Int J Pharm Pharm Sci 2016;8:102.

17. Yang T, Sheng HH, Feng NP, Wei H, Wang ZT, Wang CH. Preparation of andrographolide-loaded solid lipid nanoparticles and their in vitro and in vivo evaluations: characteristics, release, absorption, transports, pharmacokinetics, and antihyperlipidemic activity. J Pharm Sci 2013;102:4414-25.

18. Bothiraja C, Shinde MB, Rajalakshmi S, Pawar AP. Evaluation of molecular pharmaceutical and in vivo properties of spray-dried isolated andrographolide-PVP. J Pharm Pharmacol 2009; 61:1465-72.

19. Guo L, Kang L, Liu X, Lin X, Di D, Wu Y, et al. A novel nanosuspension of andrographolide: Preparation, characterization and passive liver target evaluation in rats. Eur J Pharm Sci 2017;104:13-22.

20. Rajani M, Shrivastava N, Ravishankara MN. A rapid method for isolation of andrographolide from Andrographis paniculata Nees (Kalmegh). Pharm Biol 2000;38:204-9.

21. Sharma M, Sharma RG. Identification, purification and quantification of andrographolide from Andrographis paniculata (Burm. F.) nees by HPTLC at different stages of lifecycle of crop. J Curr Chem Pharm Sci 2013;3:23-32.

22. Dendisova M, Jenistova A, Parchanska-Kokaislova A, Matejka P, Prokopec V, Svecova M. The use of infrared spectroscopic techniques to characterize nanomaterials and nanostructures: a review. Anal Chim Acta 2018;1031:1-14.

23. Lee LC, Liong CY, Jemain AA. A contemporary review on data preprocessing (DP) practice strategy in the ATR-FTIR spectrum. Chemom Intell Lab Syst 2017;163:64-75.

24. Assi RA, Darwis Y, Abdulbaqi IM, Asif SM. Development and validation of a stability-indicating RP-HPLC method for the detection and quantification of azithromycin in bulk, and selfemulsifying drug delivery system (SEDDs) formulation. J Appl Pharm Sci 2017;7:20-9.

25. Trivedi A, Dixit N, Jhade DN. Modified quantification through highperformance liquid chromatography analysis for canagliflozin and metformin hydrochloride in bulk and tablets using eco-friendly green solvents. Int J Appl Pharm 2017;9:97-101.

26. Pallavi K, Srinivasa BP, Kishore BG. Development and validation of UV spectrophotometric method and RP-HPLC method for estimation of capecitabine in bulk and tablet dosage forms. Int J Appl Pharm 2016;8:24-9.

27. Kumar PR, Rajeevkumar R. A validated analytical HPLC method for the quantification of lincomycin hydrochloride in bulk and solid dosage form. Int J Appl Pharm 2017;9:42-4.

28. Shanmugasundaram P, Cholaraja B, Ragan G, Sankar Ask, Sumithra M. Analyitcal method development and validation of reversed-phase high-performance liquid chromatography for the determination of modafinil in bulk and pharmaceutical dosage forms. Asian J Pharm Clin Res 2016;9:177.

29. Shivali G, Praful L, Vijay G. A validated fouriert ransform infrared spectroscopy method for quantification of total lactones in Inula racemosa and Andrographis paniculata: quantification of lactones in herbal extracts by FT-IR. Phytochem Anal 2012;23:171-6.

30. Singh PK, Hasan T, Prasad O, Sinha L, Raj K, Misra N. FT-IR spectra and vibrational spectroscopy of andrographolide. J Spectrosc 2006;20:275-83. 